\title{
Euclides da Cunha e a cor local: a pintura da história de Canudos
}

Eduardo Wright Cardoso*

Resumo: Publicada em 1902, a obra Os sertões, de Euclides da Cunha, tornou-se um clássico da reflexão e interpretação da realidade brasileira e, por extensão, ensejou o desenvolvimento de uma extensa fortuna crítica e analítica. O objetivo deste artigo é sugerir, pois, uma chave de leitura adicional, que consiste em refletir sobre a produção euclidiana a partir do recurso narrativo da cor local. Embora amiúde associada à questão da construção da nacionalidade, o mecanismo da cor local dispõe igualmente de outras implicações e efeitos textuais que dizem respeito à dimensão imagética da narrativa. A partir dos critérios da nacionalidade e da visibilidade textual, procura-se investigar não somente a produção de Euclides, além de parte de sua fortuna crítica ao longo do século XX. Como hipótese, então, sugere-se que a cor local é parte constitutiva do campo discursivo que compreende não somente a escrita euclidiana, mas também é perceptível nas avaliações de seus comentadores. Por sua vez, a presença do critério da cor local permite sugerir a importância do investimento imagético na prosa do autor e identificar um topos específico na fortuna crítica relativa à produção euclidiana.

Palavras-chave: Euclides da Cunha. Cor local. Retórica pictórica. Escrita da história.

"Doutor em História Social da Cultura pela Pontifícia Universidade Católica do Rio de Janeiro - PUC-Rio - e professor de Teoria da História na mesma instituição. Essa pesquisa foi financiada pela Coordenação de Aperfeiçoamento de Pessoal de Nível Superior - CAPES. E-mail: edu.wright@gmail.com. 


\section{Euclides da Cunha: leitor da história nacional}

Eleito para ocupar a cadeira de número sete da Academia Brasileira de Letras (ABL), Euclides da Cunha, como era costume nos discursos de recepção, discorre sobre seus ocupantes prévios: o patrono, Antônio Frederico de Castro Alves; e o fundador da cadeira, Antônio Valentim da Costa Magalhães. Ainda que sua fala esteja voltada, sobretudo, para a vida e a produção de Valentim Magalhães, ao tratar do renomado poeta Castro Alves, Euclides permite entrever um motivo que contempla não apenas sua própria produção intelectual, mas igualmente a fortuna crítica de sua obra: os embates e as sobreposições, que reaparecem sob inúmeras formas, entre a produção poética e a produção científica. De acordo com Luiz Costa Lima, por exemplo, a recepção de Os sertões é perpassada por um topos que foi construído imediatamente após a publicação da obra, em 1902: trata-se da concepção de que o livro maior de Euclides seria, simultaneamente, uma obra científica e literária (COSTA LIMA, 1997, p. 15-16).

O topos, como mencionado, é perceptível também na oração de ingresso, proferida em 1906: o engenheiro Euclides alega um certo desconforto e roga aos novos pares: "Avaliai, portanto, os meus embaraços ao ocupar a cadeira de Castro Alves". Ainda que, nos dizeres de Manuel Bandeira, Euclides tenha sido um "poeta bissexto" (BANDEIRA, 1966, p. 629), no seu discurso de ingresso, o escritor confessa já ter se desviado "[...] dessa literatura imaginosa, de ficções, onde desde cedo se exercita e se revigora o nosso subjetivismo [...]" (CUNHA, 1966, p. 206). Distanciando-se da produção literária, Euclides é capaz, então, de avaliar, com autoridade, a situação da produção científica. Seu diagnóstico, todavia, é severo: "[...] porque assim como não temos uma ciência completa da própria base física da nossa nacionalidade, não temos ainda uma história”. $\mathrm{Na}$ sequência da fala, o escritor justifica-se:

Temos anais, como os chineses. À nossa história, reduzida aos múltiplos sucessos da existência político-administrativa, falta inteiramente a pintura sugestiva dos homens e das coisas, ou os travamentos de relações e costumes que são a 
imprimidura indispensável ao desenho dos acontecimentos (CUNHA, 1966, p. 208, grifos nossos). ${ }^{1}$

A terminologia utilizada para criticar a produção historiográfica e científica é importante: Euclides faz referência aqui à "pintura sugestiva dos homens e das coisas”, à "imprimidura indispensável” e ao "desenho dos acontecimentos". Acredito que esses termos não sejam circunstancias ou fortuitos. Ao contrário, o emprego do que poderia ser denominado de uma retórica pictórica - conjunto de expressões que remetem ao caráter pictórico ou visual da narrativa - pode indicar uma determinada inscrição de Euclides em um contexto discursivo específico, relacionado, no caso, à cor local. Neste artigo, pois, pretendo sugerir que seria possível pensar o recurso narrativo da cor local como uma chave-de-leitura para abordar a prosa euclidiana. Isso permite compreender parte dos efeitos identificados pela crítica na narrativa de Euclides e, inclusive, demonstrar a estabilidade de um topos receptivo na fortuna crítica de sua obra.

Com esse intuito, o texto encontra-se dividido em três momentos: na parcela inicial, procuro discorrer brevemente sobre as acepções vigentes de cor local durante o século XIX e, sobretudo, as implicações que podem ser associadas aos seus usos nesse momento. $\mathrm{Na}$ sequência, tentarei aventar os modos pelos quais a cor local pode ser aproximada do texto euclidiano. Para isso, creio ser possível atentar não somente para a escrita euclidiana, mas igualmente para a recepção de sua obra. Isso encaminha ao terceiro momento, no qual, a partir da fortuna crítica de Os sertões, procuro ressaltar o caráter visual e pictórico identificado por leitores coetâneos e posteriores da obra principal de Euclides - o que, afinal, permitiria demonstrar a importância do vocabulário pictórico expresso na citação anteriormente exposta a presença do critério da cor local como um índice regulador da produção euclidiana.

\section{A cor local - acepções e implicações}

Embora cor local seja uma categoria de difícil definição, é importante, para demonstrar sua validade como chave-de-leitura 
para a obra euclidiana, sugerir algumas disposições preliminares e elementos característicos. $\mathrm{O}$ mecanismo surge, originalmente, nas discussões acerca da pintura no contexto francês e, ainda no século XVIII, passa a ser incorporado como requisito nos discursos literário e historiográfico. Nesse momento, a cor local já assume a forma de um critério que legitima ou infirma os relatos e textos abordados por comentadores e críticos. Se, no contexto nacional, as disputas concentram-se na segunda metade do Oitocentos, em âmbito francês, elas são anteriores e remontam à primeira parcela do século. Além disso, em língua francesa, a cor local é motivo de deliberações e debates mais amplos e detalhados, o que oferece maiores subsídios para sua compreensão e mapeamento neste artigo. Vladimir Kapor, referindo-se ao contexto literário francês, constata que o mecanismo narrativo enseja a criação de um duplo topos: uma variante profunda e outra superficial de cor local, ou seja, textos nos quais ela estaria presente ou ausente (KAPOR, 2009, p. 101).

Dentre as elucubrações acerca do mecanismo narrativo que eram conhecidas no então período imperial brasileiro, é possível identificar as apreciações de Ferdinand Denis e Ferdinand Wolf. Denis, por exemplo, no seu Résumé de l'histoire littéraire du Portugal, suivi du résumé de l'histoire littéraire du Brésil [Resumo da história literária de Portugal, seguido do resumo da história literária do Brasil], evoca a cor local (DENIS, 1826, p. 262, p. 329, p. 490) como um recurso significativo e utiliza também a variação "cor mais verdadeira” (DENIS, 1826, p. 494). O crítico ainda emprega amiúde expressões como "pintura dos sentimentos", "pintura animada dos costumes [moeurs] selvagens", "pintura natural", "pintura exata do caráter nacional", "pintura simples", "pintura de seu país" e "pintura fiel”, para apreciar a produção literária de Portugal e do Brasil (DENIS, 1826, p. 36, p. 197, p. 219, p. 264, p. 341, p. 353, p. 486, p. 566).

Além dele, é válido mencionar o historiador e crítico literário austríaco Ferdinand Wolf, autor de Le Brésil littéraire: histoire de la littérature brésilienne [O Brasil literário: história da literatura brasileira], publicado em 1863. O crítico austríaco emprega a cor local (WOLF, 1863, p. 18, p. 21, p. 30, p. 150, p. 210, p. 220) e cunha expressões variantes como "cor original”, "cor nacional”, "cor 
científica”, "cor épica”, “cor patriótica” e "cor mais histórica”, entre muitas outras (WOLF, 1863, p. 66, p. 72, p. 85, p. 91, p. 195, p. 236). Os dois autores parecem operar no mesmo universo linguístico ao qual pertencerão, na virada do século, tanto Euclides quanto uma parcela de seus debatedores e críticos; universo este que possui na cor local uma referência fundamental.

A multiplicação de variações e desdobramentos relativos à acepção do mecanismo narrativo contrasta com a escassez teórica que envolve seu emprego. De acordo com Kapor, a cor localé uma noção subteorizada (KAPOR, 2009, p. 1). Muito empregado, o dispositivo foi pouco discutido conceitualmente. Dessa forma, sua investigação requer a elaboração de um instrumental que, por um lado, permita identificar e mapear seu emprego nas fontes e, por outro, forneça subsídios para uma leitura retrospectiva do recurso. Aqui, portanto, almejo oferecer uma alternativa para identificar e circunscrever o mecanismo da cor local e, em seguida, busco sugerir uma abordagem que possibilite desdobrar as relações intrínsecas a ele.

Para empreender uma aproximação inicial ao dispositivo, creio ser válido sugerir uma definição que, forçosamente, será provisória e, portanto, estará sujeita a retificações: segundo Jan Kamerbeek Jr., a cor local encontra-se dotada de uma expressão narrativa oriunda das discussões pictóricas e que tem por objetivo destacar aquilo que identifica e caracteriza um tempo e um espaço específicos para um país ou uma nação (KAMERBEEK Jr. apud ESCARPIT, 1986, p. 399). ${ }^{2}$ Nesse sentido, a cor local revela-se um instrumento dotado de um acentuado rigor cronológico, na medida em que sua evocação é concebida como uma forma de evitar o anacronismo. Esse escopo parece explícito na crítica que Benjamin Constant elabora, empregando o critério da cor local, acerca da historiografia dos séculos XVIII e XIX. Para o escritor, muitos historiadores "não possuem [...] a cor nem dos tempos, nem dos lugares que eles descrevem. Os eventos pertencem às épocas passadas, os atores são da nossa idade. Felizmente, os Srs. Guizot, de Barante e Thierry fundaram uma outra escola" (CONSTANT, 1829, p. 143).

O aspecto relevante é que a consolidação da cor local como critério e recurso fundamental no século XIX está associada diretamente ao desenvolvimento da nação; a cor local é parte dos esforços 
de organização da temporalidade e de delimitação da espacialidade intrínsecos a esse processo. Carine Fluckiger sublinha a relação entre cor local e nação ao explicar o surgimento do recurso como uma nova possibilidade de representar esta entidade que progressivamente deixa de ser abstrata e torna-se mais sensível e concreta (FLUCKIGER, 1995, p. 46). A determinação da nacionalidade é, pois, um elemento implícito e fundamental para a compreensão da cor local e, neste artigo, oferece um primeiro critério para sua identificação. Em perspectiva análoga, Temístocles Cezar procurou abordar a cor local como parte de uma poética da história nacional (CEZAR, 2002), enquanto Maria da Glória de Oliveira considera brevemente o uso do mecanismo na historiografia nacional (OLIVEIRA, 2009, p. 48-49).

No entanto, gostaria de enfatizar igualmente um segundo aspecto, por vezes pouco considerado, que se refere à dimensão visual inerente ao mecanismo. Sua origem pictural tende a estimular e desenvolver o aspecto icônico ou imagético da narrativa. Em outras palavras, oriunda da pintura, a cor local jamais abandona sua dimensão visualizante. Kamerbeek Jr., autor de um estudo mais detalhado acerca do recurso narrativo, procura recuperar o universo linguístico francês no qual ele está inserido no momento de seu surgimento. Para o especialista, a cor local encontra-se relacionada e vinculada a outros termos e expressões, como cor, local, verdade, vestimenta [costume], tinta, tom, estilo, fisionomia, marca [cachet] e espírito. (KAMERBEEK Jr., 1962, p. 9-24). Duas tendências diferentes estão na origem da expressão: a tradição do genius saeculi e Zeitgeist, correntes no século XVII, se soma, durante o Oitocentos, à tradição teatral e pictural do costume que, por sua vez, remete tanto ao modo de se vestir quanto à reprodução de usos e costumes. A partir daí, a expressão - amiúde empregada no plural - é adotada em seu sentido literal no contexto da pintura e, algum tempo depois, já com o significado figurado, ingressa no vocabulário literário (KAMERBEEK Jr., 1962, p. 33-35). Se a noção francesa de "costume" está na base da cor local, é importante reconhecer que ela foi deliberadamente substituída e abandonada. Os adeptos do recurso da cor local, ao adotarem a nova expressão, ou antes, ao atribuírem um novo sentido a uma expressão já existente, 
buscavam expressar algo diverso (HOVENKAMP, 1928, p. 34). A opção pelos termos cor e local, todavia, parece acentuar o vínculo entre a pintura e o texto. Hovenkamp procura sintetizar:

Reproduzir as cores, isto é, pintar com palavras aquilo que toca os sentidos, em particular aquilo que encanta os olhos e, com isso, buscar as cores mais características, as mais originais, as mais locais, dos países e dos tempos que devem diferir profundamente daqueles do autor, eis o que os Românticos vangloriavam-se de fazer ao darem o nome de "cor local" a um dos elementos mais essenciais de sua estética (HOVENKAMP, 1928, p. 36).

Assim, no domínio vasto da narrativa textual - no qual se inserem a obra de Euclides da Cunha e os textos de seus críticos e comentadores - e valorizando os contatos com a dimensão visual, a cor local indica uma representação vívida, capaz de abarcar, sugere Kamerbeek Jr., o pitoresco e a ressurreição da vida (KAMERBEEK Jr., 1962, p. 35, p. 48-56).

Partindo dessa constatação, é possível recorrer à contribuição de Paul Ricoeur, para quem os traços do imaginário, passíveis de serem explicitados originalmente pela narrativa de ficção, que configuram o entrecruzamento entre a ficção e a história, podem ser identificados na expressão "afigurar-se que...”. Uma modalidade disso ocorre com o empréstimo direto tomado à função metafórica do "ver-como", ou seja, é possível ler um livro de história como se ele fosse um romance (RICOEUR, 1997, p. 322-323). A consequência desta "permuta" entre gêneros, um exemplo da refiguração cruzada, é explicitada pelo filósofo:

O historiador não se proíbe, então, "pintar” uma situação, "restituir" uma cadeia de pensamento e dar a esta a "vivacidade" de um discurso interior. Reencontramos, desse ponto de vista, um efeito de discurso sublinhado por Aristóteles em sua teoria da lexis: a "elocução" ou a "dicção", segundo a Retórica, tem a virtude de "colocar diante dos olhos" e, assim, de "fazer ver". [...]. Entramos na área da ilusão, que, 
no sentido preciso do termo, confunde o "ver-como" com um “crer-ver” (RICOEUR, 1997, p. 323-324, grifos do autor).

Ricoeur explora aqui uma potencialidade da metáfora indicada por Aristóteles, que é, justamente, a condição de "fazer ver". Além disso, a valorização de expressões como vivacidade e pintura, e do efeito do seu emprego, é fundamental para a proposta a ser sugerida neste artigo. Assim, outro critério que pode ser associado à cor local refere-se ao seu efeito visualizante, resultado derivado da vivacidade da narrativa. O próprio Ricoeur, alhures, aprofunda o argumento, constatando o entrecruzamento da legibilidade e da visibilidade na representação historiadora, o que possibilita, dessa maneira, abordar um dos principais efeitos do emprego da cor local. As narrativas permitem não só entender, mas também ver (RICOEUR, 2007, p. 276).

A ênfase nessa dimensão visual oferece a possibilidade de ampliar as implicações relacionadas à cor local - por vezes, demasiado limitada à questão da nacionalidade. Não se trata, evidentemente, de recusar a associação entre cor local e nação, mas antes de sugerir que o recurso narrativo não deve ser resumido a esse critério. $\mathrm{O}$ alargamento, enfim, dos caracteres atribuíveis à cor local, isto é, a incorporação da dimensão imagética, permite, a partir de outro viés, oferecer uma alternativa para sua apreensão como um objeto de pesquisa. A fim de circunscrevê-la, creio ser possível sugerir que o recurso enseja e participa do que poderia ser denominado de retórica pictórica, isto é, um extenso, mas limitado conjunto de expressões que remetem ou integram o vocabulário pictórico, tais como colorido, pintura, desenho, debuxo, quadro, imagem, entre outras. Esses vocábulos, recorrentes no discurso de ingresso na $\mathrm{ABL}$ e em diversos textos de Euclides, indicam, pois, a presença do critério da cor local. A composição desse léxico pictural foi a maneira encontrada para evitar uma apreensão demasiado subjetiva do objeto. Dessa forma, é possível construir um determinado idioma comum que permite a verificação do emprego do dispositivo narrativo. ${ }^{3}$

Em síntese, neste artigo, a cor local é concebida a partir de dois critérios ou dimensões principais: o primeiro diz respeito à determinação do tempo e do espaço e, portanto, vincula o recurso à 
constituição da nação durante o século XIX. Já o segundo comporta mais diretamente o efeito produzido por seu emprego e evidencia o caráter visual da narrativa. $\mathrm{O}$ estabelecimento desses dois critérios permite direcionar as duas parcelas seguintes do artigo. No próximo item, assim, trata-se de sugerir como Euclides aproxima-se do critério da cor local e compartilha com literatos e autores do XIX a retórica pictórica. Em seguida, na parcela final do texto, busca-se recorrer aos textos de recepção da obra de Euclides, a fim de verificar os possíveis efeitos desencadeados, nos leitores, pela prosa euclidiana.

\section{A produção euclidiana - cor local como demanda nacional}

Ao investigar a composição de Os sertões, Leopoldo Bernucci identifica, precisamente, a importância dos diálogos travados por Euclides com autores românticos e, assim, atesta a presença do dispositivo narrativo. Nas suas palavras:

Na urdidura de todas as linhas do romantismo, contempla-se
por um lado os traços mais gerais de Alencar, Castro Alves,
Walter Scott e Hugo e, por outro, os particulares: a cor local,
o compromisso com a sociedade, as fortes radicalizações
entre o Bem e o Mal, o exotismo e outros (BERNUCCI,
1995, p. 37).

Francisco Foot Hardman, embora sem mencionar a cor local, procura identificar, nos escritos euclidianos, uma polaridade pouco investigada que diz respeito "[...] a um romantismo de base, de matriz hugoniana, que provoca em sua prosa e poesia uma interessante combinação entre estética do sublime, dramatização da natureza e da história e do discurso socialmente empenhado" (HARDMAN, 1996, p. 294). Em relação à constituição da identidade nacional, Costa Lima advoga que Euclides encontrava-se vinculado aos românticos. Nos seus termos: "[...] o essencialismo nacionalista que os românticos cultivaram, sob as vestes do sentimento e da fantasia e não 
com o suposto respaldo, veio a se cristalizar sob o evolucionismo de Euclides” (COSTA LIMA, 1997, p. 45).

As constatações de Bernucci, Hardman e Costa Lima, que aproximam Euclides de autores como José de Alencar e Victor Hugo, abreviam, mas não substituem, a trajetória a ser desenvolvida. É necessário demonstrar, pois, a inscrição da cor local na produção do escritor fluminense. Para João Cezar de Castro Rocha, os estudos euclidianos, embora bastante desenvolvidos, ainda carecem da delimitação do campo discursivo com o qual Euclides dialogou na elaboração de seu principal texto (CASTRO ROCHA, 2004, p. 212-213). Não se trata aqui, evidentemente, de almejar tão largo escopo, mas de sugerir apenas que esse campo discursivo é composto, também, pela cor local e pela retórica pictórica.

É possível encontrar evidências do registro da cor local, concebida como um critério discursivo da nacionalidade, na coletânea de artigos denominada Contrastes e confrontos, de 1907. No texto Plano de uma cruzada, Euclides aborda o embate que seria necessário travar contra a natureza desértica nacional, responsável por obstaculizar o desenvolvimento da civilização. As secas e os desertos, aponta o escritor, imporiam desafios para a abordagem de artistas e para a atuação de políticos e cientistas. No artigo, o escritor fluminense aponta os limites do conhecimento científico e a ausência de um projeto político que arroste a situação:

Diante da enorme fatalidade cosmológica, temos uma atitude de amadores [...]. Daí a instabilidade e o baralhamento dos juízos. Acompanhamos o fenômeno escravizados à sua cadência rítmica; não lhe antepomos à intermitência a continuidade dos esforços. Entretanto, o próprio variar das causas precipitadas nos revela a sua feição complexa, exigindo longos e pacientes estudos (CUNHA, 1966, p. 132).

Por ora, o que pretendo discutir não é a recorrente percepção euclidiana da insuficiência científica em relação às mazelas nacionais (diagnóstico expresso, como escrito anteriormente, também em relação à produção historiográfica brasileira), mas a convicção de que esse projeto de atuação, simultaneamente científico e político, 
demanda uma realização eminentemente nacional. $\mathrm{Ou}$, dito de outro modo, como se trata de um embate contra o clima, essa campanha necessita ser levada a cabo por brasileiros (CUNHA, 1966, p. 132). Ainda que escassas, as tropas nacionais dispõem de precedentes. Euclides procura recordar os esforços cientificistas de pioneiros como Ricardo Franco de Almeida Serra, Silva Pontes e Lacerda e Almeida. Não obstante, acrescenta o escritor fluminense, esse primeiro impulso do conhecimento nacional foi refreado pelo próprio processo político de busca pela autonomia, ou seja, ao conquistar a independência sobre o espaço, o Brasil, paradoxalmente, perdeu o território. Nos seus termos:

Mas, precisamente ao adquirirmos a autonomia política - talvez porque com ela ilogicamente se deslocasse toda a vida nacional para os litorais agitados - olvidamos a terra; e os esplendores do céu, e os encantos das paisagens, e os deslumbramentos recônditos das minas, e as energias virtuais do solo, e as transfigurações fantásticas da flora, entregamo-los numa inconsciência de pródigos sem tutela, à contemplação, ao estudo, ao entusiasmo, e à glória imperecível de alguns homens de outros climas (CUNHA, 1966, p. 134-135, grifos nossos).

O equívoco maior, portanto, refere-se à delegação do empreendimento científico sobre a formação física nacional a sábios de outras paragens, "homens de outros climas". Afinal, a busca e o domínio da terra demandam um investimento que seja oriundo da própria nacionalidade. A sequência do excerto do Plano de uma cruzada procura demonstrar o acanhado desenvolvimento dos estudos científicos nacionais, assoberbados por sotaques, sons e nomes adventícios. Ouçamos Euclides:

Ao nosso nativismo nascente - e já ouriçado com os estilhaços dilaceradores da Noite das Garrafadas, não escandalizaram os ww ensarilhados, os yy sibilantes, e os estalar dos kk, e o ranger emperrado dos rr de alguns nomes arrevesados e estranhos. Koster, John Mawe, Wied-Newied, Langsdorf, 
Aug. Saint-Hilaire... primeiros termos de uma série, onde aparecem, num constrangimento de intrusos, raros nomes brasileiros - e que veio quase interrupto até Frederico Hartt, e que aí está contínua, imperecível e fecunda com Eugen Hussack, Orville Derby e Emilio Goeldi (CUNHA, 1966, p. 135 , grifos nossos).

A constatação de uma produção nacional que se vê tolhida ou obstaculizada por nomes ou influxos estrangeiros não é original. $\mathrm{O}$ excerto de Euclides parece ecoar, ao contrário, o afamado manifesto de José de Alencar, cujo objetivo era, igualmente, pleitear a validade e a importância de um fazer literário caracteristicamente nacional, isto é, dotado de cor local. Em Benção Paterna, texto introdutório ao romance Sonhos d'ouro (1872), Alencar discorre sobre a formação da literatura nacional. Um dos temas abordados é a purificação da língua "brasileira", que paulatinamente começava a distinguir-se do idioma português. Alencar afirma:

[...] a manga, da primeira vez que a prova, acha-lhe o estrangeiro gosto de terebintina; depois de habituado, regala-se com o sabor delicioso. Assim acontece com os poucos livros realmente brasileiros: o paladar português sente neles um travo; mas se aqui vivem conosco, sob o mesmo clima, atraídos pelos costumes da família e da pátria irmãs, logo ressoam docemente aos ouvidos lusos os nossos idiotismos brasileiros, que dantes lhes destoavam a ponto de os ter em conta de senões (ALENCAR, 1959, p. 701).

Alencar encerra o texto com a seguinte indagação: "[...] o povo que chupa o caju, a manga, o cambucá e a jabuticaba, pode falar uma língua com igual pronúncia e o mesmo espírito do povo que sorve o figo, a pera, o damasco e a nêspera?" (ALENCAR, 1959, p. 702). Ambos, Alencar e Euclides, reivindicam, pois, a legitimidade dos saberes poético e científico no momento de afirmação do caráter nacional.

$\mathrm{Na}$ cruzada perante o clima inimigo, os soldados brasileiros, em menor número, assemelham-se a estrangeiros, invasores. Embora 
sem o mencionar explicitamente, Euclides parece recuperar, em Plano de uma cruzada, o topos do desterrado em sua própria terra. Seu intuito é explanar a incipiência não apenas da ciência, mas também da produção artística nacional. ${ }^{4} \mathrm{O}$ arremate do artigo, que evidencia a retórica pictórica, é significativo:

Não admiram o incolor, o inexpressivo, o incaracterístico, o tolhiço e o inviável na nossa arte e das nossas iniciativas: falta-lhes a seiva materna. As nossas mesmas descrições naturais recordam artísticos decalques, em que o alpestre da Suíça se mistura, baralhado, ao distendido das landes [...]. É que a nossa história natural ainda balbucia em seis ou sete línguas estrangeiras, e a nossa geografia física é um livro inédito (CUNHA, 1966, p. 135, grifos nossos).

Euclides não se aproxima apenas do programa literário - explicitamente construído a partir do critério da cor local - sugerido por Alencar. Nesse trecho, ao denunciar a ausência de "seiva materna", o escritor fluminense parece recuperar uma das normatizações fundamentais relativas ao emprego da cor local, elaborada em 1827, por Victor Hugo. ${ }^{5} \mathrm{O}$ escritor e crítico francês procurava prescrever, ainda que versando sobre a produção dramática, o emprego da cor local. Nas suas palavras:

Não é só na superfície do drama que deve estar a cor local, mas no fundo, no coração mesmo da obra, onde ela se transborda para fora de si mesma, naturalmente, igualmente, e, por assim dizer, para todos os cantos do drama, como a seiva que sobe da raiz à última folha da árvore (HUGO, 1864, p. 34). ${ }^{6}$

Dessa perspectiva, as proposições de Euclides podem ser aproximadas, por um lado, da definição normativa da cor local (expressão da "matriz hugoniana" mencionada por Hardman) e, por outro, do programa estético-literário expresso por José de Alencar. No entanto, os indícios da presença do mecanismo narrativo em sua produção não se esgotam aí. Ao reivindicar um conhecimento produzido por 
brasileiros, o autor parece resgatar também um anseio expresso pelos sócios e integrantes do Instituto Histórico e Geográfico Brasileiro (IHGB) que requeriam a produção de uma história nacional a partir da pena brasileira. Tristão de Alencar Araripe, por exemplo, em texto publicado na Revista do $I H G B$, em 1894, refere-se amiúde à nacionalidade do responsável pela redação da história:

O escritor brazileiro pois, que pretender escrever a istoria da nossa patria, terá em consideração dezenhar a figura respeitavel dos nossos omens benemeritos, de maneira que excitem em nossos corações o amor para com as suas venerandas sombras, e persuadam-nos quanto é doce a recompensa da virtude pela gratidão da posteridade (ARARIPE JÚNIOR, 1894, p. 263).

Menos de uma década depois, Euclides ingressa no IHGB e, nessa ocasião, reitera a importância do pertencimento ao Brasil, isto é, manifesta a crença de que a nacionalidade brasileira asseguraria, por si só, a qualidade da análise ou dos trabalhos da produção científica. Assim, ao apresentar-se, em 1903, diante dos novos pares historiadores, Euclides declara: "[...] - posso vir, placidamente, para o vosso meio, trazendo uma qualidade única e irredutível, mas que por si supre por outras, e que no momento atual, para ter algum valor, deve ser isolada - a qualidade de brasileiro" (CUNHA, 1966, p. 418). Na sequência da fala, Euclides reconhece que essa virtude, contudo, não é fornecida pelo fortuito nascimento ou pelos atributos de uma Constituição, mas antes por um esforço consciente ou uma espécie de aclimatação histórica (CUNHA, 1966, p. 419).

Se, na virada do século, Euclides ainda parece ecoar tanto os projetos histórico-geográficos desenvolvidos pelo IHGB quanto os anseios literários expressos por Hugo e Alencar, é necessário acrescentar que seu programa, isto é, sua cruzada, propõe-se a ser mais abrangente, ao menos da perspectiva territorial. $\mathrm{O}$ espaço, para o escritor fluminense, não deveria se restringir à região costeira; era imprescindível investigar e mapear outras regiões. Conforme sugere no terceiro e último artigo da série que compõe o Plano de uma cruzada, era necessário ultrapassar a abordagem exclusivamente 
litorânea - aliás, insuficiente exatamente porque excluía o espaço no qual a identidade nacional poderia se consolidar: "[...] deslumbrados pelo litoral opulento e pelas miragens de uma civilização, que recebemos emalada dentro dos transatlânticos, esquecemo-nos do interior amplíssimo onde se desata a base física real da nossa nacionalidade" (CUNHA, 1966, p. 140). Para Euclides, portanto, o projeto desenvolvido pelo IHGB, cujo objetivo era desvelar a nacionalidade, permanecia válido. No entanto, o foco do olhar precisava ser corrigido: tratava-se de abandonar o litoral, espaço caracterizado por uma civilização de empréstimo, e direcionar os esforços para o sertão, local que detém o fundamento da nacionalidade brasileira (CUNHA, 1966, p. 140).

Esta abordagem da obra de Euclides procurou, em resumo, sugerir que o escritor fluminense opera com a retórica pictórica e considera o critério da cor local como fundamental para a elaboração de sua produção intelectual. Inúmeras evidências demonstram isso. Como procurei sugerir, Euclides ainda partilha dos projetos histórico-geográficos veiculados pelo IHGB, ao mesmo tempo em que, ecoando Alencar e Hugo, defende uma produção, artística ou científica, de caráter eminentemente nacional. Se, contudo, o foco da abordagem é deslocado da produção para a recepção da obra euclidiana, seria possível identificar, acredito, não apenas a demanda pelo investimento nacional, mas ainda outra implicação do emprego da cor local, o investimento no caráter imagético da narrativa.

\section{A recepção euclidiana - cor local como construção imagética}

Como mencionado, o recurso da cor local também pode ser expresso a partir da dimensão que diz respeito mais diretamente ao elemento visual do texto. Nesse sentido, a recepção da obra de Euclides permite identificar o efeito associado ao recurso narrativo e a inscrição de críticos e comentadores no campo discursivo que compreende a retórica pictórica. $\mathrm{O}$ destino do texto não deve ser, afinal, desconsiderado. Conforme salienta Fernando Nicolazzi, o 
leitor é parte da operação de legitimação da própria narrativa e do ofício histórico. Nas suas palavras, é importante "[...] levar em consideração que, ao se falar em escrita da história, não se deve perder de vista que esta história também é lida e que o ato de leitura ali implicado é parte constitutiva do que se pode chamar conhecimento histórico" (NICOLAZZI, 2010, p. 544-545).

Essa legitimação, acredito, deriva também do efeito imagético proporcionado pela narrativa ou, tal como havia mencionado Ricoeur, do desenvolvimento da visibilidade a partir do texto. Bérenger Boulay, em perspectiva análoga, procura demonstrar que a historiografia francesa contemporânea, a partir de nomes como Georges Duby, Arlette Farge e Alain Corbin, vale-se, na elaboração textual, de efeitos diversos. Todos derivam da noção latina evidentia, cujo pressuposto é colocar sob os olhos do leitor ou do espectador aquilo que é descrito ou narrado (BOULAY, 2010, p. 27).

A fortuna crítica de Euclides, ao longo do século XX e mesmo no início do século XXI, oferece então um expediente importante para a avaliação de sua obra e para a verificação da sugestão exposta neste artigo: a participação da cor local no campo discursivo de Euclides. Para Walnice Galvão, seria possível identificar três fases principais na recepção de Os sertões: um momento inicial, composto pelos maiores críticos literários da época, como José Veríssimo, Araripe Júnior e Sílvio Romero, no qual predomina a visão literária; um segundo momento, nutrido nas ciências sociais, que agrega as leituras de Gilberto Freyre, Antonio Candido e Olímpio de Sousa Andrade, e, por fim, um terceiro momento, que se inicia na década de 1980 e conta com as abordagens de Luiz Costa Lima, Roberto Ventura e, seria possível acrescentar, João Cezar de Castro Rocha, a própria Walnice Galvão, entre outros (GALVÃO, 2016, p. 613-614).

Desde a publicação de Os sertões, é possível perceber que a cor local permanece como um critério regulador da escrita euclidiana, na medida em que os comentadores e críticos destacam e valorizam os procedimentos descritivos, sejam eles relativos aos indivíduos, à paisagem ou ao conflito - e isso no mesmo momento no qual Euclides admoestava os historiadores, tal como expresso no discurso de admissão na ABL, a elaborar uma "pintura sugestiva dos homens e das coisas" e a realizar "um desenho dos acontecimentos". É o caso, 
por exemplo, da leitura realizada por José da Penha e publicada, na Gazeta de Notícias, em dezembro de 1902:

No delinear dos tipos, em que o Sr. Euclides se compraz, repetidas vezes, não há que se lhe reparar: o debuxo sai-lhe completo e vívido. Moreira César, Thompson - o valente, o probidoso, o liberal Thompson Flores; Tupi, Tamarindo, o competente Febrônio, a vítima da teimosia vaidosa do conselheiro Luís Viana -, tudo foi descrito com propriedade de cores (PENHA, 2003, p. 33, grifos nossos).

Leopoldo de Freitas, por sua vez, destaca a abordagem psicologizante elaborada pelo engenheiro fluminense, em um breve comentário no Diário Popular do mesmo período: “[...] em Os sertões, o conhecimento da psicologia do sertanejo é descrita com a vivacidade do colorido que só um artista iniciado nos segredos da estética dos assuntos camponeses poderia apresentar com tamanha opulência" (FREITAS, 2003, p. 36, grifos nossos). A prosa euclidiana poderia ser caracterizada, então, como imagética. Múcio Teixeira, por exemplo, em uma série de artigos no Jornal do Brasil, de 1903, não hesita em comparar as imagens elaboradas por Euclides, tanto a pinturas quanto a fotografias. Ao comentar as descrições de alguns militares, Teixeira assevera: "[...] a página consagrada à caricatura do heroísmo tem a energia das perduráveis sátiras juvenalescas e uns vivos reflexos do claro-escuro das telas de Rembrandt [...]"; e, em seguida, quando o foco de Euclides recai sobre o coronel Antônio Moreira César, o crítico acrescenta: "[...] é fiel como uma fotografia este estranho perfil do singular e bizarro epilético [...]” (TEIXEIRA, 2003, p. 43-44, grifos nossos).

A apologia ao descritivo euclidiano resiste inclusive aos exames mais severos de sua obra. Refiro-me ao juízo publicado pelo afamado crítico literário José Veríssimo, no Correio da Manhã, em dezembro de 1902. O comentarista condena, inicialmente, a linguagem excessivamente técnica da obra; não obstante, procura também exaltar o estilo adotado na escrita, composto de "reais qualidades de escritor, força, energia, eloquência, nervo, colorido, elegância [...]”. Mesmo o trecho dedicado integralmente à descrição do espaço mereceu 
elogios: a descrição da terra é "animada e vívida" (VERÍSSIMO, 2003, p. 47). Para concluir a apreciação, o crítico, enfim, manifesta: "[...] o sr. Euclides da Cunha fez daquela campanha uma pintura vigorosa e um estudo que estava por fazer" (VERÍSSIMO, 2003, p. 54, grifos nossos). Os atributos elencados por Veríssimo, como "força", "energia", "eloquência", "colorido", "animado" e "vívido", parecem indicar a visibilidade proporcionada pelo recurso da cor local e a sua inscrição no campo discursivo da retórica pictórica.

Os diversos posicionamentos arrolados têm em comum tanto a exaltação do procedimento descritivo construído pelo escritor fluminense quanto o imediatismo das leituras. Silvio Romero, após ofertar sua apreciação nos jornais do período, procurou posteriormente elaborar uma crítica fundamentada que foi lida na cerimônia de posse de Euclides na ABL, em 1906. Mesmo neste momento, o teor do exame permanece semelhante. Como Euclides estava presente, Romero interpela-o diretamente: "Vós sabeis retratar ao vivo a natureza física, dando intensidade às notas, sem prejudicar a veracidade dos fatos, a qualidade dos fenômenos”. E acrescenta: "[...] é o grande escolho da arte da descritiva: exatidão e relevo, naturalismo e brilho, consistência e colorido, poesia e verdade" (ROMERO, 2003, p. 139, grifos nossos).

Romero felicita o novo membro da agremiação: "[...] a Academia recebe em seu seio um poderoso escritor, mas um que pode colocar ideias, além de pronomes, porque estuda e medita, porque sabe ver e inquirir" (ROMERO, 2003, p. 145, grifos nossos). Não se trata do primeiro elogio à capacidade visual do escritor fluminense. José Veríssimo já havia enaltecido a mesma virtude. Nas suas palavras: Euclides "[...] sabe ver e descrever [...]" (VERÍSSIMO, 2003, p. 46, grifos nossos). Afinal, para possibilitar a visão de outros, de seus leitores, é importante - embora não indispensável - que o agente dessa visão seja capaz, também ele, de ver. Walnice Galvão, ao abordar o ineditismo da cobertura jornalística da guerra de Canudos, destaca justamente a importância da iniciativa de se enviar um indivíduo para cobrir os eventos no local em que se passaram: "[...] a utilização da figura do enviado especial, ou seja, um jornalista que vai observar pessoalmente os eventos no próprio local, é quase uma novidade no Brasil da época” (GALVÃO, 1999, p. 154). 
É significativo, todavia, que o destaque fornecido à dimensão visual da prosa euclidiana não se restringe às avaliações imediatas de Os sertões. De modo diverso, é possível identificar apreciações análogas mesmo na bibliografia especializada do final do século XX e início do século XXI - o terceiro momento da fortuna crítica, tal como mencionado por Galvão. Em texto publicado originalmente em 1994, a especialista na obra euclidiana também destaca o caráter visual em Os sertões, ao salientar a elaboração narrativa do autor. Nas suas palavras:

Este é um daqueles livros em que é difícil, se não empresa vã, separar o autor do narrador. Primeiro, porque o narrador não se ficcionaliza, nem mesmo ao portar a persona do tribuno. É sempre a voz do autor [...] que estamos ouvindo, este autor que fala diretamente ao leitor em plural majestático. Depois, porque o tom panfletário de denúncia coloca ante os nossos olhos um tribuno da plebe discursando, o tribuno Euclides da Cunha e não um narrador que seja seu sucedâneo ou porta-voz (GALVÃO, 2016, p. 630-631, grifos nossos).

Em Bernucci, a constatação de que a narrativa de Os sertões permite ao leitor visualizar os acontecimentos ocorre em dois momentos. Inicialmente, na aproximação que o autor estabelece entre o modo descritivo de Euclides e, um dos sistematizadores da cor local, Victor Hugo (BERNUCCI, 1995, p. 34). Em seguida, a percepção do efeito visual adquire a forma de uma advertência ao leitor desavisado. Essa passagem, creio, merece ser reproduzida:

[...] sabe-se que o autor d'Os Sertões, mais de uma vez, narrou cenas que não viu como se tivesse sido seu observador argucioso. Não causam, portanto, nenhuma admiração ao leitor as vivas descrições da natureza pintada pelo escritor segundo os modelos que as fontes livrescas lhe ofereceram muito antes de sua ida a Canudos. Basta olhar as páginas de 'A Nossa Vendeia' para nos darmos conta de que Euclides era mestre em transformar simples e longínquas impressões 
visuais em dados minuciosos e concretos aos olhos [...]. Com efeito, para o leitor incauto, através da linguagem estonteante e persuasiva de Euclides, a representação da natureza chega a ser tão perfeita e detalhada, e despeito de sua factibilidade, que o que passa a adquirir importância parece já não ser propriamente o que se narra mas como se narra (BERNUCCI, 1995, p. 107).

A rica formulação de Bernucci permite destacar precisamente o efeito visual proporcionado por sua escrita: independente de sua presença diante dos eventos, Euclides concede, ao leitor, a visualização da "pintura sugestiva dos homens e das coisas". Seria importante explorar, como afirma Bernucci, os modos e expedientes empregados pelo escritor fluminense nesse processo. No entanto, neste artigo, limito-me à constatação dessa evidência que, na fortuna crítica da obra euclidiana, reaparece de modo constante.

Berthold Zilly, especialista e tradutor da obra euclidiana, por sua vez, destaca em Os sertões "[...] a irresistível capacidade de evocar e presentificar o passado teatralmente". Para o especialista, o escopo de Euclides é "[...] preparar o intelecto do leitor para uma recepção extremamente sensorial, visual, acústica e emocional daqueles quadros lancinantes de que dificilmente consegue se livrar”. E, em seguida, acrescenta:

[...] paradoxalmente, Euclides não abre mão da busca da Verdade e da História [...], uma história apesar de seus meandros e contradições, evocada e encenada pela magia da palavra que (re)cria telas, desenhos, fotografias, cenas teatrais, reais ou imaginadas. (ZILLY, 1998, s/p).

Castro Rocha, enfim, ao destacar o esforço euclidiano para o mapeamento da nação, define sua escritura:

[...] vale dizer, uma escrita cartográfica que torna visível com palavras em lugar de traços, como se fosse um diligente mapa da terra ignota [...]. Há, portanto, o mapa sugerido com traços e o mapa delineado com palavras (CASTRO ROCHA, 2004, p. 179, grifos do autor). 
Se as caracterizações se repetem e, a despeito das críticas ou elogios, mantêm uma certa uniformidade, sua reprodução aqui procura atestar a inscrição da produção euclidiana e de sua recepção dentro de um regime que destaca a visualidade do texto, notadamente quando se refere aos tipos sociais e às paisagens. $\mathrm{O}$ que se depreende dessas manifestações é a partilha de um vocabulário que orbita em torno da retórica pictórica e, de modo específico, indica a presença da cor local. Esse campo discursivo pictural pode ser encontrado, como visto, tanto no texto euclidiano quanto nas próprias apreciações dos comentadores. A estabilidade dessa leitura indica, pois, a existência de um topos na recepção da obra euclidiana que diz respeito à capacidade visual intrínseca ao texto. Leitores de Euclides de diferentes períodos, críticos e entusiastas parecem ser igualmente observadores da "pintura sugestiva" da história de Canudos.

\section{Considerações finais - A pintura sugestiva da história}

Este artigo teve início com a fala de Euclides no momento de seu ingresso na ABL. Ao avaliar a produção científica nacional na abertura do século XX, e a escrita da história em particular, Euclides emprega um vocabulário de ordem imagética. Essa retórica pictórica permite identificar, acredito, alguns dos elementos que participam do campo discursivo euclidiano e que, nesse caso, podem ser aproximados do recurso narrativo da cor local. Em outras palavras, a cor local poderia ser pensada como uma chave de leitura útil para se refletir sobre a produção euclidiana, sobretudo quando se enfatiza dois de seus critérios principais: a bem conhecida demanda pelo caráter nacional - expressa nos textos prescritivos e críticos de Euclides - e o, ainda pouco explorado, investimento imagético que decorre de seu emprego - tal como se observa na recepção e fortuna crítica de Os sertões.

Nesse sentido, a estabilidade desta leitura que destaca e enaltece a visibilidade que se depreende do texto euclidiano permitiria, inclusive, sugerir uma espécie de constante receptiva em relação à sua obra. Costa Lima, como citado anteriormente, identificou um topos na recepção de Os sertões que diz respeito ao duplo registro 
da obra, científico e literário. Análises mais recentes, acredito, têm procurado apontar e destacar, ora a dimensão artística-literária da obra, ora sua composição científica. Assim, para ilustrar a vitalidade do topos identificado por Costa Lima, seria possível esboçar uma distinção na bibliografia evocada neste artigo: Bernucci tende a valorizar os componentes imaginativos e ficcionais de Os sertões, enquanto o próprio Costa Lima procura evidenciar os componentes científicos do texto - ainda que sem desconsiderar as dimensões literárias. É necessário apontar, todavia, que o destaque de uma das vertentes não implica a dissolução do topos, mas, ao contrário, a sua ratificação. Afinal, a abordagem continua a operar, em grande medida, com os mesmos vetores esboçados no início do século XX.

Creio ser possível sugerir, como mencionado, uma segunda constante receptiva à leitura do livro, que se concentra precisamente no efeito desencadeado pelo seu singular "estilo": o texto euclidiano permitiria ao leitor ver o que é narrado ou descrito. A percepção da visibilidade é apontada pelos leitores coetâneos à publicação do texto (como Tristão de Alencar Araripe, José Veríssimo e Silvio Romero) e perdura, através das décadas, mesmo em leituras recentes (como as de Leopoldo Bernucci, Berthold Zilly, Walnice Galvão e Castro Rocha). Considerar a cor local como um dos elementos que possibilitam o investimento na visibilidade textual permite, por um lado, ampliar a abordagem sobre o próprio recurso narrativo e, por outro, no caso da obra de Euclides, enseja a elaboração de uma chave-de-leitura para sua obra e a evidenciação de um topos receptivo na sua fortuna crítica. Nesse sentido, enfim, Euclides parece fazer um uso específico da cor local, seja ao sugerir a importância do investimento nacional na produção científica e artística, seja ao prescrever e elaborar uma "pintura sugestiva dos homens e das coisas" na sua exposição do "desenho dos acontecimentos" relativos à Guerra de Canudos.

\section{EUCLIDES DA CUNHA AND THE LOCAL COLOUR: THE PAINTING OF THE HISTORY OF CANUDOS}

Abstract: Published in 1902, Euclides da Cunha's work Os sertões became a classic of reflection and interpretation of the Brazilian reality and led to the 
development of an extensive critical and analytical fortune. Therefore, the purpose of this article is to offer another possible way of reading his writings from the standpoint of the narrative feature called local colour. Although often associated with the issue of nationality, the local colour also has other implications and textual effects that are related to the imagery dimension of the narrative. From the criteria of nationality and textual visibility, I will seek to investigate not only the Euclides' writings, but also part of his critical fortune throughout the twentieth century. I intend to propose, as a hypothesis, that the local colour is a distinguish part of the discursive field that comprises not only the Euclidean writings, but is also perceptible in the evaluations of its commentators. In turn, the presence of the local colour allows to suggest the importance of the imagery investment in the author's prose and to identify a specific topos in the critical fortune of his work.

Keywords: Euclides da Cunha. Local colour. Pictorial rhetoric. Writing of history.

\section{Notas}

${ }^{1}$ Procurei preservar a grafia original na transcrição de todas as fontes deste artigo. Para as referências em outras línguas, ademais, utilizei uma tradução livre. ${ }^{2}$ Acredito que seja fundamental compreender a cor local como um mecanismo vinculado, simultaneamente, ao tempo e ao espaço durante o século XIX. Isso porque o dispositivo permanece vigente contemporaneamente, contudo, concentrado preferencialmente sobre sua dimensão espacial, como se verifica, por exemplo, em dicionários de termos literários de língua inglesa. Assim, no Dicionário Penguin, "local color" implica o emprego de detalhes peculiares a uma região particular ou ambiente, de modo a adicionar interesse e autenticidade à narrativa (CUDDON, 1999, p. 476). Por sua vez, no Dicionário Oxford, a cor local encontra-se associada a um tipo de ficção ligada a uma comunidade regional (BALDICK, 2001, p. 142-143). Seria válido especular sobre o abandono dessa marca temporal do mecanismo. E acredito que a resposta possa envolver a aceleração temporal que se verifica, no contexto nacional, a partir da segunda metade do século XIX. Demasiado instável, o tempo torna-se efetivamente inapreensível.

${ }^{3}$ A elaboração dessa linguagem relativa à cor local se assemelha à seleção, empreendida por Franco Moretti, de palavras-chaves que, em comunhão com uma prosa específica, permitem identificar as peculiaridades da cultura burguesa na linguagem literária dos séculos XVIII e XIX (MORETTI, 2013, p. 18-19).

${ }^{4} \mathrm{O}$ topos é, de fato, mencionado em um artigo intitulado Nativismo provisório (CUNHA, 1966, p. 188).

Anos 90, Porto Alegre, v. 25, n. 47, p. 279-304, jul. 2018 
${ }^{5}$ Definição fundamental na medida em que o mecanismo é marcado por uma teorização apenas lacunar. Para Kapor, duas delimitações são basilares para a normatização da cor local: além desta, de autoria de Hugo no texto intitulado La Préface de Cromwell, é possível mencionar a de Benjamin Constant, citada anteriormente (KAPOR, 2003, p. 3).

${ }^{6}$ Euclides era um admirador efusivo da obra de Victor Hugo, tendo inclusive dedicado-lhe poemas e crônicas. Bernucci (1995, p. 25-38) e Andrade (2002, p. 245) discorrem sobre a importância de Hugo para a obra euclidiana.

\section{Referência}

ALENCAR, José de. Obra completa. Rio de Janeiro: Editora José Aguilar, vol. 1, 1959.

ANDRADE, Olímpio de Souza. História e interpretação de Os sertões. Rio de Janeiro: Academia Brasileira de Letras, 2002.

ARARIPE JÚNIOR, Tristão de Alencar. Indicações sobre a historia nacional. Revista do IHGB, Rio de Janeiro, t. 57, parte 2, p. 259-290, 1894.

BALDICK, Chris. The concise Oxford dictionary of literary terms. Oxford: Oxford University Press, 2001.

BANDEIRA, Manuel. Os poemas de Euclides da Cunha. In: CUNHA, Euclides da. Obra completa. Rio de Janeiro: Companhia José Aguilar Editora, vol. 1, 1966.

BERNUCCI, Leopoldo. A imitação dos sentidos: prógonos, contemporâneos e epígonos de Euclides da Cunha. São Paulo: Editora da Universidade de São Paulo, 1995.

BOULAY, Bérenger. Effets de présence et effets de vérité dans l'historiographie. Littérature, n. 159, p. 26-38, 2010.

CASTRO ROCHA, João Cezar de. O exílio do homem cordial: ensaios e revisões. Rio de Janeiro: Museu da República, 2004.

CEZAR, Temístocles. L'écriture de l'histoire au Brésil au XIX siècle. Essai sur une rhétorique de la nationalité. Le cas Varnhagen. Tese (Doutorado em história). Paris: EHESS, 2 vols., 2002.

CONSTANT, Benjamin. Réflexions sur la tragédie [...]. Revue de Paris. Bruxelles: Demengeot et Goodman. tomo 7, 1829, p. 132-147.

COSTA LIMA, Luiz. Terra ignota: a construção de Os sertões. Rio de Janeiro: Civilização Brasileira, 1997. 


\section{Eduardo Wright Cardoso}

CUDDON, J.A. The Penguin Dictionary of literary terms and literary theory. London: Penguin Books, 1999.

CUNHA, Euclides da. Obra completa. Rio de Janeiro: Companhia José Aguilar Editora, vol. 1, 1966.

DENIS, Ferdinand. Résumé de l'histoire littéraire du Portugal, suivi du résumé de l'histoire littéraire du Brésil. Paris: Lecointe et Durey Libraires, 1826.

ESCARPIT, Robert. Dictionnaire international des termes litteraires. Berne: A. Francke, 5v., 1986.

FACIOLI, Valentim; NASCIMENTO, José E. (Orgs.). Juízos críticos. Os Sertões e os olhares de sua época. São Paulo: Nankin Editorial: Editora da Unesp, 2003.

FLUCKIGER, Carine. L'histoire entre art et science: la "couleur locale" chez Thierry et Barante. Université de Genève. Mémoire de licence, 1995.

FREITAS, Leopoldo. Os sertões. In: FACIOLI, Valentim; NASCIMENTO, José E. (Orgs.). Juízos críticos. Os Sertões e os olhares de sua época. São Paulo: Nankin Editorial: Editora da Unesp, 2003, p. 35-37.

GALVÃO, Walnice. "Euclides da Cunha: Os sertões”. In: MOTA, Lourenço Dantas (Org.). Introdução ao Brasil: um banquete no trópico. São Paulo: Editora SENAC, p. 151-170, 1999.

GALVÃO, Walnice. Fortuna crítica. In: CUNHA, Euclides da. Os sertões - edição crítica. São Paulo: Ubu Editora: Edições Sesc São Paulo, v. 1, 2016, p. 609-686.

HARDMAN, Francisco Foot. Brutalidade antiga sobre história e ruína em Euclides. Estudos avançados. São Paulo: EdUSP, v. 10, n. 26, p. 293-310, 1996.

HOVENKAMP, J.W. Mérimée et la couleur locale. Contribution à l'étude de la couleur locale. Paris: Libr. les Belles Lettres, 1928.

HUGO, Victor. Oeuvres Complètes. Drame. Paris: Alexandre Houssiaux: Libraire-éditeur, tomo 1, 1864.

KAMERBEEK Jr., Jan. Tenants et aboutissements de la notion de "couleur locale". Utrech: uitgave van het, Instituut voor vergelijkend literatuuronderzoek aan de rijksuniversiteit te utrecht, 1962.

KAPOR, Vladimir. Exotisme et couleur locale - essai d'une analyse constrastive des champs sémantiques respectifs. Proceedings, France and the Exotic. University of Birmingham, p. 1-11, 2003.

. Local colour: a travelling concept. Bern: Peter Lang AG, 2009.

MORETTI, Franco. The bourgeois: between literature and history. London; New York: Verso, 2013.

Anos 90, Porto Alegre, v. 25, n. 47, p. 279-304, jul. 2018 
NICOLAZZI, Fernando. Como se deve ler a história? Leitura e legitimação na historiografia moderna. Varia história. Belo Horizonte, v. 26, n. 44, p. 523-545, jul./dez., 2010.

OLIVEIRA, Maria da Glória de. Escrever vidas, narrar a história. A biografia como problema historiográfico no Brasil oitocentista. Tese (Doutorado em história). Rio de Janeiro: UFRJ, 2009, p. 48-49.

PENHA, José da. “Um livro!”. In: FACIOLI, Valentim; NASCIMENTO, José E. (Orgs.). Juízos críticos. Os Sertões e os olhares de sua época. São Paulo: Nankin Editorial: Editora da Unesp, 2003, p. 26-34.

RICOEUR, Paul. Tempo e narrativa. Campinas: Papirus, tomo 3, 1997.

. A memória, a história, o esquecimento. Campinas: Editora da UNICAMP, 2007.

ROMERO, Sílvio. Discurso. FACIOLI, Valentim; NASCIMENTO, José E. (Orgs.). Juízos críticos. Os Sertões e os olhares de sua época. São Paulo: Nankin Editorial: Editora da Unesp, 2003, p. 123-158.

TEIXEIRA, Múcio. Euclides da Cunha - Campanha de Canudos. In: FACIOLI, Valentim; NASCIMENTO, José E. (Orgs.). Juízos críticos. Os Sertões e os olhares de sua época. São Paulo: Nankin Editorial: Editora da Unesp, 2003, p. 42-45.

VERÍSSIMO, José. Uma história dos sertões e da campanha de Canudos. In: FACIOLI, Valentim; NASCIMENTO, José E. (Orgs.). Juízos críticos. Os Sertões e os olhares de sua época. São Paulo: Nankin Editorial: Editora da Unesp, 2003, p. 46-54.

WOLF, Ferdinand. Le Brésil littéreire: histoire de la littérature brésilienne [...]. Berlin: A. Asher \& Co., 1863.

ZILLY, Berthold. A guerra como painel e espetáculo. A história encenada em Os sertões. História, Ciências, Saúde - Manguinhos. Rio de Janeiro, v. 5, supl., jul., 1998, s/p.

Recebido em: 27/05/2017

Aprovado em: 30/11/2017 